\title{
FORMAÇÃO DE ESPAÇO EDUCATIVO PARA A CONSTRUÇÃO DE CONHECIMENTO COMPREENSIVO SOBRE O PROCESSO DE SAÚDE
}

\author{
Iris Fenner BERTANI ${ }^{1}$
}

\begin{abstract}
RESUMO: Elaborou-se sistemática de intervenções sobre a compreensão da saúde pública como questão social por meio da criação de espaço de compartilhamento com a comunidade. Iniciou-se a construção do ensinamento participativo entre a população, profissionais e acadêmicos a respeito dos mitos e realidades sobre o conhecimento empírico e o científico na área da saúde pública no município de Franca e região. O objetivo foi proporcionar a experiência do debate crítico sobre as questões da saúde como objeto concreto, introduzindo como esforço consciente, a reflexão dos determinantes sociais e o ideário ético-político, vinculados à definição de saúde como vida. Os pesquisadores prepararam-se para o trabalho de condução não-diretiva para a coordenação de cada debate. Realizaram reuniões mensais, divulgadas por cartazes afixados na Universidade e nas Unidades de Saúde de Franca. As contribuições construídas para o estudo da questão da saúde enfocaram-na mais como um produto social do que uma adversidade biológica. As avaliações positivas ao fim de cada conversa e as sugestões temáticas para os próximos encontros apontavam que o trabalho estava no caminho certo e que devia prosseguir. Podese dizer que foi possível o abandono relativo de certezas ao submetê-las a novas compreensões.
\end{abstract}

PALAVRAS-CHAVE: Saúde. Participação. Sistema Único da Saúde. Metodologia. Grupos abertos. Dialética.

\section{Introdução}

O Grupo de Estudos e Pesquisas sobre Saúde, Qualidade de Vida e Relações de Trabalho (Grupo QUAVISSS), integrado à Universidade Estadual Paulista - UNESP e certificado pelo Conselho Nacional de Pesquisa (CNPq) foi constantemente argüido para ampliar seu número de pesquisadores, de forma a compreender todos os interessados em discutir os seus temas de constituição. Diante da dificuldade em se expandir o grupo e torná-lo inoperante, considerou-se a possibilidade de se criar um espaço educativo aberto à comunidade para oportunizar a participação dos interessados e também para que fosse

\footnotetext{
${ }^{1}$ UNESP - Universidade Estadual Paulista. Faculdade de História, Direito e Serviço Social - Departamento de Serviço Social - Grupo de Estudos e Pesquisas sobre Saúde, Qualidade de Vida e Relações de Trabalho (Grupo QUAVISSS/UNESP/CNPq). Franca - SP - Brasil. 14409-160 - iris@franca.unesp.br
} 
garantida uma devolutiva dos estudos voltados à construção do conhecimento sobre saúde em nossa sociedade.

Para operacionalizar esta iniciativa, Grupo QUAVISSS organizou um evento mensal voltado ao compartilhamento e trocas de saberes sobre as questões da saúde em nossa sociedade. Escolheu utilizar uma metodologia que abrigasse em seu conteúdo, a idéia da intervenção para a transformação social. Certamente difícil embora certamente possível.

Partimos da compreensão do conceito saúde no Brasil legalizado na Constituição Federal de 1988 como um direito social. Esta confirmação da saúde no elenco dos direitos sociais fundamentais brasileiros representa um marco dentro do Estado Democrático, destinado a assegurar o exercício tanto dos direitos sociais, como individuais. O direito à saúde é então garantindo “[...] mediante políticas sociais e econômicas que visem à redução do risco de doença e de outros agravos e ao acesso universal e igualitário às ações e serviços para sua promoção, proteção e recuperação.” (BRASIL, 1998, p.104).

A saúde, ao deixar de ser vista apenas como o “contrário da doença” é entendida no Brasil como um valor comum de cidadania, ou seja, constitutivo da humanidade, abrangendo todas as classes sociais. Os fatores determinantes da saúde são considerados uma proposição global nacional direcionada à transformação das condições de vida injustas, por outras de benefício coletivo social e, como tal, elemento potencialmente revolucionário para a sociedade brasileira.

O Sistema Único de Saúde - SUS - no Brasil constitui um projeto social exclusivo no conjunto dos países em desenvolvimento (BRASIL, 2002), e ao visar a garantia da assistência universal integral e gratuita para a população como parte do Sistema de Proteção Social do país, representa elemento gerador de expansão da qualidade de vida e inclusão social da população. Outro aspecto a ser considerado é a recomendação de partilhamento da responsabilidade por condições saudáveis de vida, expressa na mesma lei 8080 em seu título I, art. $2^{\circ}$, de que “[...] o dever do Estado não exclui o das pessoas, da família, das empresas e da sociedade.” (BRASIL, 2002)

A constatação dessas proposições constitutivas de ordem legal levam à reflexões sobre a necessidade de prestar informações à população sobre seus direitos e deveres fundamentais para a preservação da vida. Introduz a perplexidade que se encerra na pergunta: o que acontece que estas idéias não são implementadas definitivamente no país, considerados cerca de 20 anos que foram idealizadas? Por que este debate essencial fica 
sufocado em atenção precária da saúde pública no país? E, ainda: conhecem os brasileiros, este seu direito?

Com base neste referencial, reconheceu-se o distanciamento da população às propostas construídas no país sobre as ações de saúde. Da mesma forma pode-se supor que o conhecimento intuitivo leigo sobre a atenção à saúde pública, ao se deparar com o sucateamento dos recursos disponibilizados pelo Estado para a área, não identifique a relação intrínseca entre o conceito de saúde e as ações praticadas em seu entorno. Não há a apropriação direta do contexto social-cultural de sujeito que aprende saúde pela simples experimentação do real vivido. Todavia, o Grupo QUAVISSS, apostou na premissa de que a realidade possível, ao ser objeto de análise como concreto pensado transforma-se em instrumental suscetível de intervenção educativa social. Recusa-se a visão do homem como uma entidade abstrata, e da legislação como um sonho delirante, irrealizável, e coloca no lugar o sujeito de direitos com capacidade de tornar nova uma realidade social insatisfatória, superando as condições de vida determinadas por uma estrutura ideológica perversa que a reproduz constantemente.

Considerou-se a educação como força geradora da superação do sistema de exploração social para a coesão social, eqüidade e redução da pobreza. A partir do consenso sobre essas perspectivas pareceu fundamental o trabalho didático participativo de construção do conhecimento (GIL, 2005) para um aporte interventivo, ou seja, conhecercompreender-transformar. A persistência das questões de desigualdade e pobreza, iniqüidade social e desemprego estrutural são considerados fatores determinantes das doenças, eles mesmos podendo ser configurados como doença social.

\section{Descrição da metodologia utilizada nas conversas}

Criou-se uma atividade de extensão acadêmica de troca de informações e debates, denominada "Conversas interessantes sobre saúde", coordenada pelo Grupo QUAVISSS. Como o próprio nome da atividade sugere, a iniciativa está voltada a conversar com a população sobre os diversos aspectos da saúde, as políticas públicas que regem suas ações e as estratégias que vem sendo adotadas para a implantação definitiva dos princípios e diretrizes do SUS. Talvez, um pouco de pretensão supor que as conversas seriam de fato interessantes, mas a denominação sugere um desejo: não aulas expositivas formais, mas 
trocas sobre observações empíricas, formadas no concreto sentido e intuitivamente construídas em direção ao pensamento mais complexo, o concreto pensado, a capacidade de realizar abstrações e construir novas utopias.

Para viabilizar esta ação, ficou decidido que as conversas teriam uma ordenação temática e que a coordenação das sessões ficaria sob responsabilidade de duplas de participantes do Grupo QUAVISSS que apresentassem interesse e disponibilidade de se prepararem e discutirem previamente entre si como conduzir os trabalhos.

As conversas foram efetivadas mensalmente durante todo o ano de 2007 e divulgadas por avisos em salas de aula, cartazes afixados na Universidade e nas Unidades de Saúde (UBS) de Franca e aos profissionais da cidade. O convite incluía um chamamento a qualquer público interessado a discutir e trocar idéias sobre as questões da saúde: poderiam vir e trazer amigos, amigos dos amigos, namorados, vizinhos, enfim era uma atividade aberta a quem se interessasse dela participar, para transpor as barreiras universitárias e construir pontes, o trânsito recíproco com a comunidade. Contudo, como resultado dessa convocação difundida na cidade de Franca, tivemos uma resposta muito tímida, não condizente com a procura anterior pela participação como membro do QUAVISSS. As reuniões foram então realizadas com grupos pequenos, uma média de 15 pessoas, formada preferencialmente por estudantes dos primeiros anos dos cursos oferecidos pelo Campus, movidos mais pela curiosidade ou, na maioria, interessados em um possível certificado de participação. Transmitiam a impressão de que visavam "inchar” seus currículos e não compartilhar idéias, muito menos transformar a realidade, qualquer que fosse.

Muito embora esta solicitação fosse questionável diante da metodologia e objetivos do trabalho proposto, ainda assim foram instituídos mais dois novos tópicos na organização dos eventos: o certificado de participação e um documento de avaliação por sessão. Este último, construído com a finalidade de indicar os aspectos que ainda precisavam ser aperfeiçoados na metodologia aplicada, e que apontassem a direção a ser seguida no prosseguimento das conversas.

A introdução de cada novo assunto dependeu de um aquecimento do grupo, sendo que as reuniões foram programadas para se dar num espaço de tempo de 2 horas de duração no período vespertino, das $17 \mathrm{~h}$ às $19 \mathrm{~h}$, uma vez por mês. Desde a primeira reunião, após as apresentações interpessoais, iniciou-se tecendo considerações mais identificadas ao tema, 
na tentativa de partir do conhecimento empírico da realidade. Assim, introduziu-se a questão da qualidade de vida, buscando um consenso inicial sobre como entender a vida adjetivada. Apresentar temática tão abrangente, objeto de tantas interpretações e interpretes sem se tornar cansativa e "doutoral-vertical", levou a desenhar uma visão panorâmica da temática, buscando ampliar tanto quanto o possível, o horizonte do debate.

A população participante continuou flutuante em sua maioria, e ainda que fossem tratados os conteúdos apontados nas avaliações como de interesse preferencial, não se observou um retorno assíduo dos demandatários do tema de cada conversa. Colocado em discussão, estas ausências foram imputadas ao fato de não haver uma aula "de verdade" durante as conversas, acrescido de que os temas escolhidos eram resultantes de uma curiosidade difusa, expressa no momento final da reunião como um objeto de interesse ligado mais à possibilidade de esclarecimento formal, científico, dos assuntos ligados à saúde. Ainda assim, manteve-se o consenso de que a dinâmica das reuniões seria não diretiva, partindo do que fosse apresentado como percepção intuída dos participantes sobre os assuntos elencados para cada vez.

Um aspecto recorrente nas discussões de preparação e avaliação das conversas pelo QUAVISSS foi a demarcação do período de tempo necessário para a discussão ser encaminhada e a necessidade pessoal de obter resultados mais verificáveis. Pareceu aos coordenadores de cada vez que tinham que dar respostas pontuais às expectativas manifestadas. Do contrário, seriam criticados pelos participantes como uma conversa "sem rumo”, à toa. Algumas vezes foi constatado o quanto o conhecimento acadêmico estava distante de prestar uma contribuição socialmente útil à comunidade.

Alguns dos coordenadores das conversas levaram o conteúdo programado para a reunião preparado como aula expositiva, utilizando recursos de informática, expediente ao qual poderiam recorrer no caso de sentirem-se "perdidos” durante a reunião. Houve quem recorresse ao expediente preparado, analisando posteriormente sua atitude como resultado da dificuldade e do medo de não conseguir encaminhar a conversa, sentindo que estavam “falhando na entrega” do conhecimento. A ideologia do balcão sobrepondo-se à vivência da construção coletiva baseada na experiência real.

Em contrapartida, apesar das dificuldades elencadas, pode-se afirmar que muito do que foi falado e apresentado, perguntado e trocado, constituiu aos poucos um novo saber, o saber de "roda", simples, direto e prático, resultado das ações que se realizam na área da 
saúde a partir do cotidiano do município de Franca e região. O exercício das proposições freirianas de participação e construção coletiva a partir do universo construído em que não há um saber preponderante por si só, levou o Grupo a renovar seus esforços na busca da práxis da aprendizagem significativa (FREIRE, 1974).

Foi um difícil exercício, esclarecer sobre a área de pesquisa e entendimento profissional sem recorrer, a cada passo, às referências teóricas que sustentam a argumentação acadêmica sobre o conhecimento da realidade e visão de mundo. Havia o compromisso preponderante de construir o conhecimento à luz da vivência da práxis, aos inúmeros determinantes e condicionantes sociais a que a questão da saúde está vinculada.

Saúde, ao ser entendida não apenas como pré-requisito da sobrevivência, mas “vida plena”, torna-se um constructo muito difícil de ser alcançado, mas nem por isso menos desejável. Na prática, é como tentar tocar um objeto móvel, que se vai delineando num crescendo, incluindo aí as novas constatações da práxis, permitindo promover reflexões e proposições interdisciplinares, extrapolando as ações pontualmente dirigidas à prevenção, tratamento e combate às doenças.

\section{Resultados obtidos ou o conteúdo das conversas:}

Qualidade de vida, nesse exercício de aprendizado mútuo, foi encontrada como resposta para quase tudo: exercícios físicos, dietas, marketing de companhias de turismo, o carro do ano, SPAS, a arte de ser feliz, o caminho do sucesso, receitas de auto-ajuda e outros tantos exemplos apropriados pela sociedade de consumo. E esta relação desordenada e até certo ponto caótica, vem demonstrar a dificuldade que é tratar desta temática. Na maioria das vezes, ela foi colocada como um bem a ser alcançado por opção, uma questão de escolha de oportunidades disponíveis e acessíveis a todos, cabendo a cada um esforçarse individualmente para alcançá-la. Como já defendemos em outro texto (BERTANI, 2001) há uma persistente ideologia voltada a estabelecer o conceito de qualidade de vida como equivalente ao saber viver, ter estilo de vida, esvaziando seu conteúdo político e social. Sobrepõe-se continuamente, nessa discussão, qualidade de vida como retorno pessoal, e o resultado ligado à capacidade crescente de consumo de bens de e artigos supérfluos, observados como distinção social por mérito. 
Foi recorrente a associação de saúde como o contrário de doenças, apesar da vinculação do conceito se dar à questão social. Lembrou-se a convivência da alta sofisticação da medicina científica atual e seus instrumentos de diagnostico e cura, com as práticas populares como benzeções, chás, 'garrafadas' e simpatias e pela busca de socorro em diversos níveis de valores da espiritualidade, culturalmente encaminhadas. Essa busca de soluções realizada de forma indiscriminada localiza a saúde no messianismo e no auxílio de curandeiros, em crenças e sessões de magia, votos e promessas. Muitas pessoas, além disso, contam como certa a efetivação, em curto prazo, dos milagres de cura de doenças prometidos pela mídia por meio da ciência moderna, das conquistas técnico-instrumentais complexas e sofisticadas, tal como a aparelhagem de "última geração" e dos novos e poderosos medicamentos, na solução de todos os males. Constatou-se nossa passiva dependência ao sistema de consumo, e o quanto a solução das doenças está diretamente ligada ao binômio dor-medicação, um dos ícones da atenção curativa do nosso tempo (LOURENÇO; BERTANI; REZENDE, 2001). Outro aspecto referido foi a estratégia de marketing das seguradoras e planos privados de saúde em suas campanhas para novos associados, contrapondo-se ao serviço público universal e gratuito como direito de cidadania.

Observaram-se as precárias condições de educação, destacou-se a situação de trabalho e as mortes por exaustão ocorridas nas poderosas usinas de beneficiamento da cana-de-açúcar. Também se salientaram as precárias condições de habitação não só do trabalhador rural, mais também do urbano, os alojamentos, a promiscuidade, e nada mais precisa ser evocado para comprovar o sistema de exclusão social como contrário ao conceito de saúde adotado formalmente no País.

Mais abrangente, a análise da situação econômica (IBGE, 2000) demonstra que, apesar do Brasil ser um país de muitos pobres em contraposição à farta disponibilidade de recursos, o problema mais constante tem sido a permanência da distribuição injusta e desigual das riquezas. Esta desigualdade, além de permear toda a possibilidade de desenvolvimento econômico e social do País, surge como condicionante da origem da pobreza, marcando a síntese sócio-histórica da saúde e da precarização contínua da qualidade de vida dos cidadãos brasileiros.

Como contribuição acrescentou-se à conversa, a compreensão de estrutura social, a centralidade do homem, ser social. Levamos à discussão o modo de ver o mundo e o 
homem como dele construtor e por ele construído. O ser humano integral - integrador da coletividade humana e de seus diferentes ambientes internos e externos de vida (LUKÁCS, 1974). Esta razão complexa da satisfação da saúde como uma necessidade humana fundamental, lembrada até antes da aspiração universal de liberdade (SEN, 2000) ao ser colocada no campo da vivência do cotidiano esbarrou em dois pré-conceitos: a de que prover saúde é uma sorte, um destino de uma constituição física bem estruturada; e a do discurso da responsabilização estritamente individual na preservação da saúde, visando em última instância, a economia de gastos públicos de forma geral, uma nova roupagem neoliberal das antigas exortações conservadoras da sociedade.

Assim é que saúde, no pensamento leigo se parece com “viver bem”, uma aspiração humana legítima, que por si só já justifica as tentativas em atendê-la, buscando-a nas possibilidades do corrente estágio da civilização. Qualidade de vida, apesar de contar com uma multiplicidade de definições, muitas vezes até complementares e repetitivas é, e deve ser relacionada com saúde, liberdade e autonomia. Quase uma definição de felicidade no senso comum, a ser obtida como bem a partir da distribuição de renda numa sociedade regida pelos modos de produção capitalista. De tal forma a abordagem neoliberal faz parte do pensar-agir da sociedade atual que parece natural que as escolhas individuais e o empoderamento do capital social da comunidade humana sejam dirigidos à posse de bens e do capital econômico (SADER, 1995).

Foi possível observar, ainda mais, alguns aspectos do cotidiano intuído pelos participantes das conversas, destacados aqui com a finalidade de elucidar a dificuldade de se criar uma sociedade mais justa. Entre elas destaque-se a percepção compartilhada que vivemos hoje um tempo de simplificação grosseira, mecânica e consumista do que seria um estado de bem viver, e parece que as representações atuais de saúde e qualidade de vida muitas vezes se resumem a padrões de beleza, formas físicas e posse de bens. Salientou-se que as pessoas não utilizam apenas seu lado racional nas relações com o concreto; e longe da objetividade e do pragmatismo, encaram de modo muito pessoal cada acontecimento do cotidiano, e suas emoções, socialmente construídas, influenciam seu desempenho em diversas áreas e resultados. Ao se voltar o enfoque à equação inicial, saúde - igual a condições gerais de vida determinadas e condicionadas aos complexos fatores ambientais, sociais, econômicos, culturais, psicológicos e espirituais, buscou-se pontuar a oposição à 
explicação que se desloca a sociedade do sujeito individualizado, isolando-o e culpabilizando-o pelo transtorno do adoecimento.

\section{Considerações finais}

A lógica do desenvolvimento desigual de base modernizadora e concentradora de capital de um lado, e excludente e produtora de miséria de outro vem solapar as recomendações da Carta Magna de 1988, que destaca as condições necessárias para obtenção do estado de saúde (BRASIL, 1988)

O conceito saúde rege as questões políticas, prevê o continuum na elaboração e aplicação de Políticas Públicas, empresta atenção aos aspectos socioeconômicos e sócioculturais. Envolve, ainda, cuidados de vigilância sanitária e epidemiológica, atende as necessidades apresentadas pelas condições de trabalho e de distribuição de renda. Pauta-se também o aspecto subjetivo-individual, considerando as expectativas pessoais e crenças pessoais, ainda que socialmente construídas. Traz, inserida na sua concepção homemmundo, a idéia de coexistência, mais do que convivência, "existir com", repartir, apoiar, amparar. Traz a relevância da não-violência, do olhar solidário, da preservação dos valores e significados humanos mais profundos, de preservação da vida.

Esta foi a principal chave desta experiência: como encaminhar a discussão sobre saúde definida como vida do ser humano no planeta Terra? A partir desse conceito abrangente e multidimensional, não há qualquer constructo sócio-cultural-econômico passível de ser realizado à margem da globalização como fenômeno plural e seu impacto sobre a sociedade. A questão da saúde, relacionada com qualidade de vida, e tema destes debates, levantada tanto pelo pensamento intuitivo de apropriação gradual da realidade (empírica) como um desejo individual, e explicado pelo pensamento complexo no conjunto das relações sociais. Estas reflexões foram consideradas instrumentos para o desenvolvimento da socialização-cidadania por meio do ensino duplamente compartilhado que a construção freiriana dialética permite (FREIRE, 1974). A transformação da sociedade, ao ser impedida insidiosamente por forças conservadoras vigentes tanto entre as camadas dominantes e reproduzidas mesmo entre as subalternas e pauperizadas, provoca um padrão de respostas localizadas fora dos sujeitos e sem nenhuma perspectiva de alteração, seja pela falta de conhecimento da estrutura social, seja pela falta de instrumental 
interventivo. Há uma dificuldade imposta globalmente, um silêncio coletivo de certa forma conivente com o arbítrio, que deixa passar questões de injustiça social, aceitando a falta de condições de superação do que é de manutenção insuportável, considerando se a garantia da cidadania.

À falta de interesse pelo exercício da participação no trato de questões vitais à própria sobrevivência da sociedade, podemos observar comportamentos de passividade e desinteresse entre os sujeitos de nossas conversas. O que torna este aspecto mais inusitado é saber que procuram o espaço de debates, diferenciando-se dos que nem ao menos tomam conhecimento dessas questões, ainda que o façam com o intuito do certificado. Não sabemos se o conteúdo provocou alguma mudança ou alteração em seu comportamento ou na visão de homem-mundo, devido à descontinuidade na freqüência às reuniões.

Ao salientar os aspectos pontuados durante o processo das conversas, considerou-se que não há ação para a transformação social se, de tudo, não acontecer o compromisso com a coletividade, no exercício do partilhamento do saber, por meio da solidariedade e respeito mútuo. Muitas conversas terão que ser realizadas, ou ainda, talvez a metodologia de trabalho possa ser alterada até definirmos a dimensão do papel político e ético do QUAVISSS na construção de um conhecimento compreensivo sobre o processo de saúde.

\title{
FORMATION OF EDUCATIVE SPACE FOR THE CONSTRUCTION OF COMPREHENSIVE KNOWLEDGE ON THE HEALTH PROCESS
}

\begin{abstract}
A systematic of interventions on the understanding of the public health as social matter was elaborated in order to create a space of sharing knowledge with the community. It was initiated by the construction of the participative teaching between the population, professionals and academics regarding myths and realities on the empirical and scientific knowledge in the public health area in Franca city and region. The objective was to provide the experience of the critical debate about health while a concrete object, introducing as conscientious effort, the reflection of social determinations and the ethicalpolitician ideals, tied with the definition of health as life. The researchers had prepared themselves for the not-directive conduction of each debate. They had promoted monthly meetings, divulged by posters affixed on the University and the Franca Units of Health. The contributions to the health question study had focused a social product more than in a biological adversity. The positive evaluations at the end of each dialogue and the thematic suggestions raised for the next meeting pointed that the work was in the right way and must go on. It can be said that the relative abandonment of certainties was possible when submitting them to new understandings.
\end{abstract}


KEYWORDS: Health. Citizen Participation. Single Health System. Methodology. Open groups. Dialectics.

\section{REFERÊNCIAS}

BERTANI, I. F. O trabalho assalariado e os processos de qualidade total. Serviço Social \& Realidade, Franca, v.10, n.2, p.47-60, 2001.

BRASIL. Constituição (1988). Constituição da República Federativa do Brasil: promulgada em 05 de outubro de 1988. Obra coletiva de autoria da Editora Saraiva com a colaboração de Antonio Luiz de Toledo Pinto e Márcia Cristina Vaz dos Santos Windt. 18. ed. São Paulo: Saraiva, 1998.

. Ministério da Saúde. Lei 8.080, de 19 de setembro de 1990. Dispõe sobre as condições para a promoção, proteção e recuperação da saúde, a organização e o funcionamento dos serviços correspondentes e dá outras providências. Disponível em: $<$ http://portal.saude.gov.br/portal/arquivos/pdf/LEI8080.pdf>. Acesso em: 20 maio 2002.

FREIRE, P. A pedagogia do oprimido. Rio de Janeiro: Paz e Terra, 1974.

GIL, L. V. Claves de educación comparada en perspectiva social. Valencia: Tirant lo Bianchi, 2005.

INSTITUTO BRASILEIRO DE GEOGRAFIA E ESTATÍSTICA [IBGE]. Pesquisa Nacional por amostra de domicílios-PNAD: síntese de indicadores 1999. Rio de Janeiro: IBGE, 2000. 1 CD-ROM.

LOURENÇO, E. A. S; BERTANI, I. F; REZENDE, R. M. A construção dos serviços de saúde e o caminho para a qualidade de vida. Serviço Social \& Realidade, Franca, v.13, n.1, p.147-174, 2001.

LUCKÁCS, G. História e consciência de classe: estudos de dialética marxista. Tradução de Telma Costa. Porto: Escorpião, 1974.

SADER, E. A hegemonia neoliberal na América Latina. In: SADER, E.; GENTILI, P. (Org.). Pós-neoliberalismo: as políticas sociais e o Estado democrático. Rio de Janeiro: Paz e Terra, 1995. p.35-37.

SEN, A. Desenvolvimento como liberdade. Tradução de Laura Teixeira Motta. São Paulo: Cia das Letras, 2000. 


\section{BIBLIOGRAFIA CONSULTADA}

BRASIL. Ministério da Saúde. Secretaria Executiva. Mais saúde: direito de todos 20082011. 2 ed. Brasília: Ed. do Ministério da Saúde, 2008. . 